\title{
Skin side effects of chlorine solutions used for hand hygiene: a systematic review
}

\author{
Z Kubilay $^{1}$, J Hopman ${ }^{1 *}$, T Allen$^{2}$, H Edrees ${ }^{1}$, B Allegranzi $^{1}$ \\ From 3rd International Conference on Prevention and Infection Control (ICPIC 2015) \\ Geneva, Switzerland. 16-19 June 2015
}

\section{Introduction}

Chlorine solutions (CS), mostly containing sodium hypochlorite $(\mathrm{SH})$, have been widely used for hand hygiene $(\mathrm{HH})$ in the West African countries affected by the Ebola outbreak due to unavailability of alcoholbased handrub solutions and soap, easiness of use and "fear" factors leading to (false) sense of safety given by using an easily available disinfectant. However, no $\mathrm{HH}$ guidelines recommend the use of CS and concerns have been raised about skin tolerability among users.

\section{Objectives}

We conducted a systematic review to investigate whether the use of CS causes skin side effects when used for $\mathrm{HH}$.

\section{Methods}

PubMed and EMBASE were searched on 26/09/14 with no time, age, human, language or geographical restrictions. Contact Dermatitis journal and the reference lists of relevant articles were also screened separately.

\section{Results}

Out of 3241 hits, 14 articles about skin side effects were included; 10 case reports, 3 surveys and one comparative study. Only one case report was related to the use of $\mathrm{SH}$ $4-6 \%$ for $\mathrm{HH}$ by a veterinary surgeon who developed allergic contact dermatitis (CD) with a positive patch test to $\mathrm{SH}$ at dilutions 100 times lower than 4-6\%. In 5 case reports, $\mathrm{CD}$ with a variable severity was reported following use of SH for disinfection (2 papers) and for domestic cleaning (3papers); these cases had positive patch tests for $\mathrm{SH}$; conversely, their experimental control groups showed either no reaction or very low-intensity skin reactions. Two papers reported severe dermatitis related to environmental cleaning with $\mathrm{SH}$, and 2 others reported unusual systemic allergic reactions with accidental exposure and bathing the foot. One comparative study showed that $\mathrm{SH}$ was the most irritating product even at low concentrations when compared to alcohol, chlorhexidine and iodine. Finally, one survey among 706 nurses showed that 33.5\% of cases of allergic or irritant CD had a history of chlorine exposure; 2 other surveys among cleaners showed higher prevalence of hand dermatitis with $\mathrm{SH}$ exposure.

\section{Conclusion}

Overall, only one report described allergic CD related to use of high-concentration CS for $\mathrm{HH}$. Very low-quality evidence shows that $\mathrm{SH}$ used for other purposes might cause skin irritations even at low concentrations following bare skin exposure.

\section{Disclosure of interest}

None declared.

Authors' details

${ }^{1}$ SDS, World Health Organization, Geneva, Switzerland. 'Library, World Health Organization, Geneva, Switzerland.

Published: 16 June 2015 